\title{
O uso da ardósia em Teotihuacan, México
}

Leila Maria França*

\author{
FRANÇA, L.M. O uso da ardósia em Teotihuacan, México. Revista do Museu de \\ Arqueologia e Etnologia, São Paulo, 17: 333-343, 2007.
}

Resumo: A indústria lapidária foi uma das atividades mais importantes em Teotihuacan. Entre os materiais mais trabalhados está a ardósia, matéria-prima importada pelos teotihuacanos, usada na elaboração de adornos, objetos de culto e, sobretudo, para acompanhar os mortos. Sua relevância social e simbólica reflete um impacto considerável no controle de zonas produtoras e rotas comerciais como também do sistema de produção artesanal, tão importantes na consolidação e manutenção do Estado teotihuacano.

Palavras-chave: Indústria lapidária - Ardósia - Teotihuacan - Mesomérica.

\section{Introdução}

T $\mathrm{m}$ dos aspectos mais marcantes da sociedade teotihuacana é o volume e a particularidade de suas atividades artísticas e artesanais, fenômeno fundamentalmente ligado ao desenvolvimento da cidade como potência comercial e religiosa (Fig. 1) da época clássica mesoamericana (150-750 d.C.)

A cerâmica teotihuacana possuía um nível de elaboração bastante sofisticado, com uma grande variedade de formas e tecnologias, e atingiu seu ponto máximo durante a Fase Xolalpan (400-650 d.C.). Por sua vez, a pintura mural é uma das manifestações "artísticas" mais destacadas dos teotihuacanos, por meio da qual, muitos aspectos daquela sociedade podem ser esclarecidos. A indústria da obsidiana era outra de suas marcas mais características, já

(*) Pesquisadora visitante no Instituto de Investigaciones Antropológicas da UNAM-Universidad Nacional Autónoma de México. Bolsista de Pós-doutorado pelo CNPq. lefranca@usp.br que o controle de sua produção e distribuição tem sido considerado um dos principais sustentáculos da expansão econômica e ideológica da cidade e de seu impacto sobre a área mesoamericana (Spence 1981).

Entre tais atividades, no entanto, o trabalho lapidário pode ser considerado um dos mais expressivos, e igualmente importante no desenvolvimento da cidade e de uma política econômica estatal, já que o comércio de longa distância - responsável pela obtenção de rochas e minerais importados - era sem dúvida um dos elementos vitais no funcionamento do Estado teotihuacano, assim como na difusão de sua ideologia religiosa (Millon 1995; 1973). Entre os materiais empregados estavam o jade e outras pedras verdes de menor valor, o quartzo, a concha, a pirita, a malaquita e outros, todos importados a Teotihuacan de diferentes pontos da Mesoamérica. A ardósia figurava entre os mais comuns.

A ardósia é uma rocha metamórfica com estrutura laminar de grãos finos de coloração 


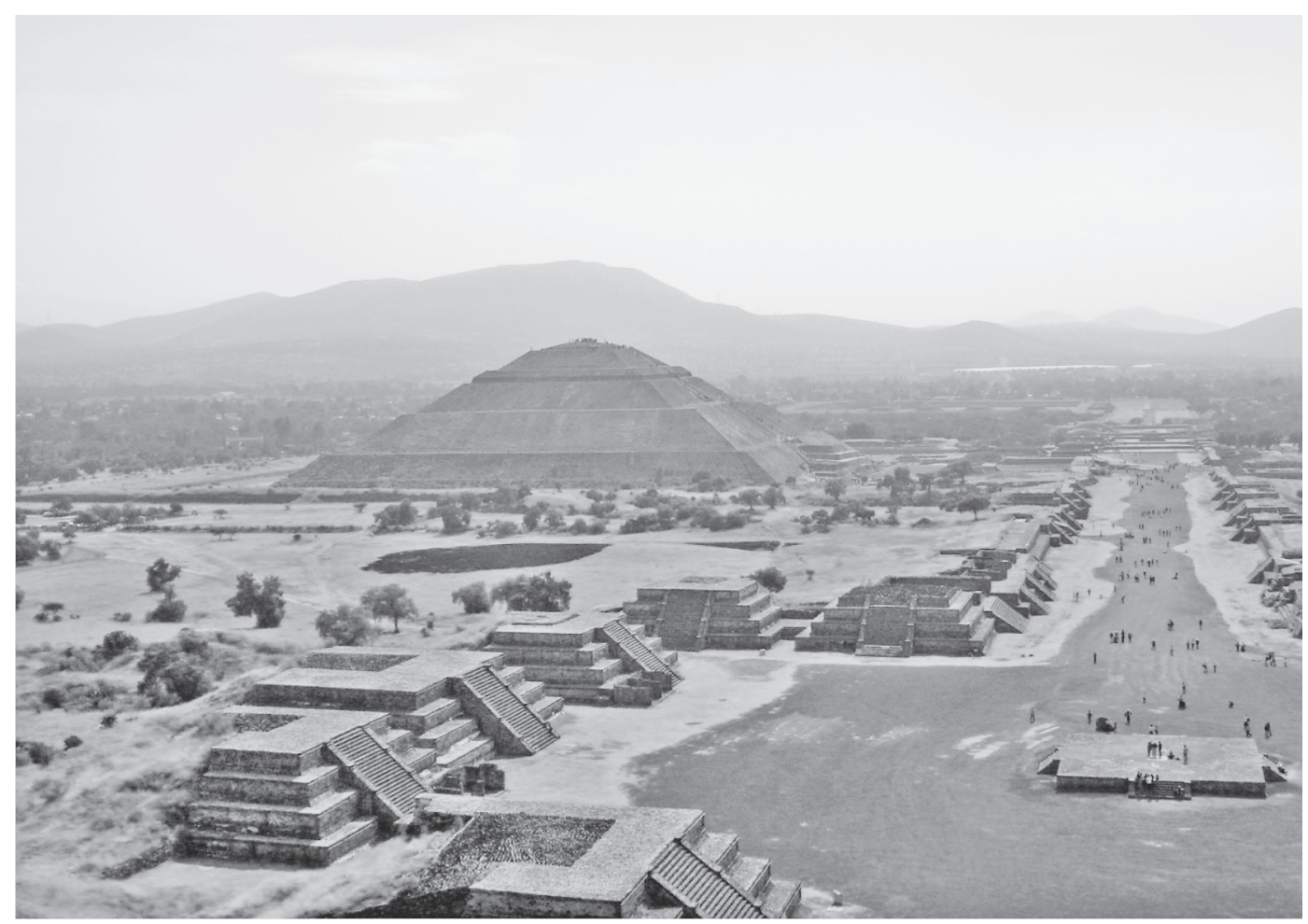

Fig. 1. Vista Parcial de Teotihuacan. Pirâmide do Sol e da Plaza de la Luna. Foto: Lucas França.

gris, alcançando tons quase negros, esverdeados, amarelentos ou castanhos avermelhados. Usada atualmente em várias partes do mundo como piso e revestimento de edifícios, em Teotihuacan a ardósia foi especialmente empregada na confecção de esculturas antropomórficas (Fig. 2), zoomórficas (Fig. 3), adornos e placas com simbolismo funerário. Esta era originária de regiões relativamente próximas ao Vale do México, provavelmente vindas dos atuais estados de Guerrero, Puebla, Oaxaca, Querétaro, Hidalgo, Chiapas, Tamaulipas e Michoacán (Cabrera Cortés 1995; López Juárez 2005).

A ardósia é encontrada em grande parte dos edifícios e estruturas da cidade, sejam públicas, laborais ou residenciais. Nas áreas, plazas e edifícios públicos, foram escavados diferentes tipos de objetos confeccionados nesse material, tais como discos polidos, discos com espelho de pirita, discos gravados com personagens estrangeiros da área da Costa do Golfo,

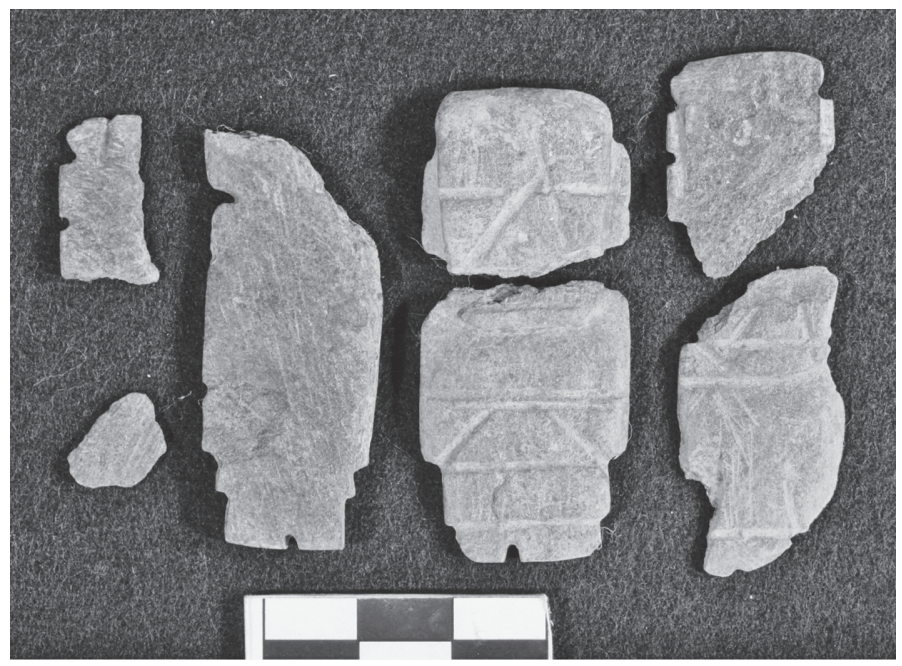

Fig. 2. Figurinhas de ardósia. La Ventilla, Frente 2.PA La Ventilla 1992. 94. Foto: Miguel Morales. 


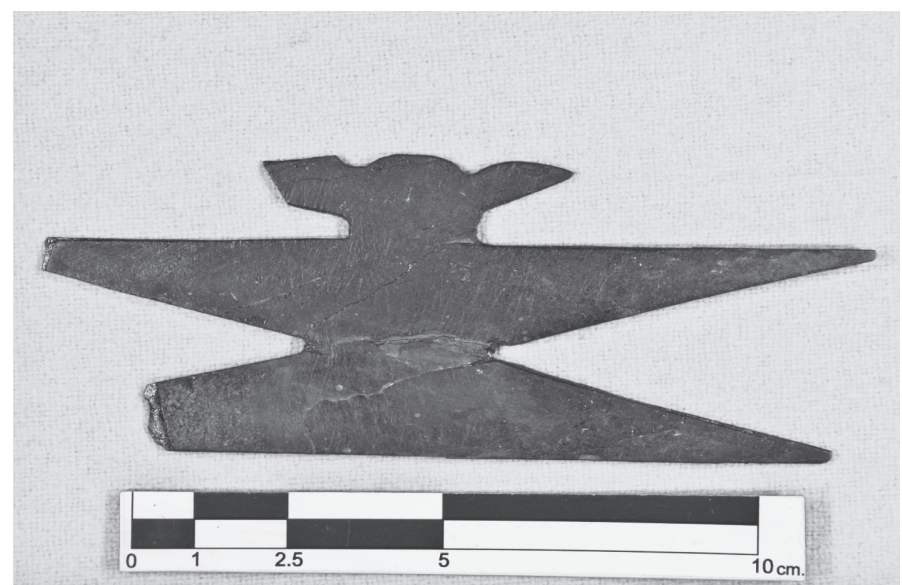

Fig. 3. Excêntrico zoomórfico de ardósia. La ventilla, Teotihuacan. Foto: Miguel Morales, ZMAT.

contas, pendentes, lâminas (a maior parte com pigmentos), aplicações e pequenas lajes que López Juarez (2005:83) caracteriza como "instrumentos de trabalho" (Fig. 4).

Nos conjuntos residenciais e centros de bairro, o mais comum é a presença das "lajinhas", figuras antropomórficas, aplicações geométricas (quadradas, circulares, retangulares, triangulares e hexagonais) que provavelmente eram usadas como incrustações em peças de vestuário - e talvez em edifícios - além de lâminas em forma de pétala ou "bico de ave" - a maioria delas com pigmento e iconografia representando faixas vermelhas em vários tamanhos e disposições. Em casos extraordinários eram usados discos com um espelho de pirita em mosaico aplicado em uma das faces, além de objetos circulares em forma de anel. Esses materiais eram especialmente depositados como oferendas funerárias em enterramentos, lembrando que, em Teotihuacan, os mortos eram enterrados no espaço doméstico, normalmente em fossas abertas dentro do piso das residências.

A ardósia é igualmente encontrada em outros contextos importantes da cidade: em áreas de atividade de oficinas lapidárias, nos recheios construtivos e em áreas de culto.

\section{Obtenção, produção e distri- buição}

Atentemos, primeiramente, para o seu contexto de produção. Como dissemos, a ardósia era um material importado, mas não sabemos com certeza o nível de "oficialização" ou de intervenção estatal de sua aquisição e na produção artesanal. É muito provável que o Estado fosse responsável pela sua aquisição em território estrangeiro assim como de toda a matéria-prima importada (pedras, minerais e conchas) empregada na indústria lapidária da cidade (Turner 1992: 107) já que esse processo envolvia o emprego de especialistas para a sua extração, um transporte adequado e protegido, bem como o controle de rotas comerciais (Gómez Chávez 2000: 566).

Entretanto, em nível de produção artesanal e de sua distribuição, se crê que havia diferentes níveis de controle (Spence 1981; Turner 1992). Por exemplo, o trabalho com um

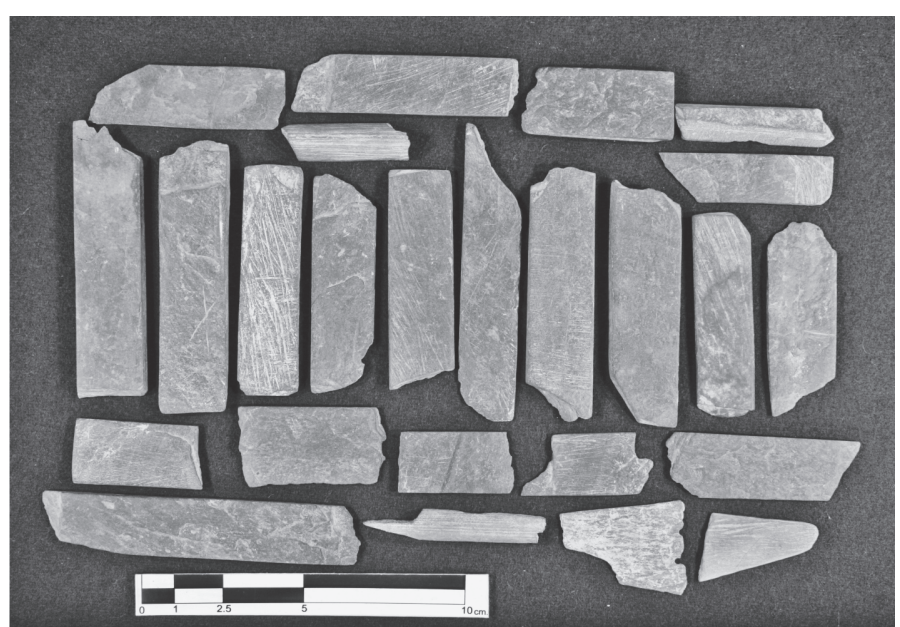

Fig. 4. Lajinhas de ardósia sem procedência. Foto: Miguel Morales. 
material valioso como a jadeíta (jade), encontrado geralmente em edifícios públicos, assim como o conjunto de técnicas empregadas em seu trabalho, sugere uma intervenção estatal importante em sua obtenção, produção e distribuição. Diferentemente, a ardósia é um material menos raro e valioso, encontrado em vários espaços da cidade, tanto oficiais quanto domésticos. Além disso, ainda que requeira alguma especialização - e de fato o conjunto de materiais revela um padrão técnico mais ou menos uniforme, com uso de percussão, pressão, desgaste, em raros casos, polimento e decoração incisa (López Juarez 2005) - não envolve grandes dificuldades de trabalho, já que é uma rocha extremamente macia.

Por essa razão, ainda que existisse uma política estatal na sua importação, não houve, provavelmente, uma centralização na produção de objetos para fins ornamentais e rituais, com exceção de alguns objetos excepcionais (Turner 1992).

A partir dos dados do Teotihuacan Mapping Project, especificamente de uma oficina lapidária de bairro (Setor N3E5) e outra próxima à Pirâmide da Lua (Setor 6G:N5W1), Turner defende a existência de dois tipos de indústria lapidária em Teotihuacan: a lapidária dos bairros, onde se trabalhava na elaboração de adornos pessoais para as camadas médias; e outra especializada, centralizada e fortemente controlada pelo Estado, onde eram elaborados os espelhos de pirita, objetos de jadeíta e de conchas valiosas como o spondylus (1992). Suas afirmações coincidem com os contextos aqui mencionados, já que a ardósia em suas variadas formas aparece em vários pontos da cidade, com exceção dos espelhos de pirita, um item mais raro, restrito a alguns enterramentos muito luxuosos.

Fragmentos, pré-formas e rejeitos de ardósia em concentrações importantes têm sido localizados em vários pontos da cidade: "Bairro dos Comerciantes”, Setor N3E5 (Turner 1988), La Ventilla (Gómez Chávez 2000), Tlajinga 33 (Widmer 1991) e nos chamados "Palácios" (residências de elite) Tetitla, Zacuala, Yahuahuala (López Juárez 2005).

Efetivamente, no chamado Bairro dos Comerciantes (Rattray 1997) escavado pela Dra.
Evelyn Rattray (1987; 1988), do Instituto de Investigações Antropológicas da UNAMUniversidade Nacional Autônoma do México, e cujo material foi revisado sistematicamente por esta pesquisadora, funcionava uma oficina lapidária onde se recuperou uma grande quantidade de fragmentos, pedras em bruto, além de vários objetos trabalhados parcialmente, a grande maioria sem pigmento - o que indica que o material se encontrava em uma etapa preliminar de trabalho. Junto a esses materiais foram escavados fragmentos de pedra dura e de navalha de obsidiana, que provavelmente eram usadas na confecção dos objetos de ardósia. Também foram recuperadas no mesmo contexto, fragmentos de serpentina e outras rochas usadas na confecção de objetos.

Tais testemunhos indicam claramente que a atividade lapidária era uma das ocupações do Bairro, além da importação das cerâmicas da Costa do Golfo - região a qual seus ocupantes estariam etnicamente filiados - da área maia e o Anaranjado Delgado, da região de Tepexi de Rodrígues, sul do atual estado de Puebla (Rattray 2001). Não se pode descartar a idéia de que os habitantes do Bairro dos Comerciantes estivessem diretamente envolvidos na importação de matérias-primas para a indústria lapidária, devido não somente à ocupação atribuída ao grupo, mas também à presença de materiais importados tanto em contexto de produção, quanto nos próprios enterramentos e oferendas do Bairro. Ricos objetos de jadeíta - um pendente de mosaico à maneira de espelho, disco e objetos ovalados - associados a um individuo do sexo feminino no Enterro 5-8, indica o acesso privilegiado a essa matéria-prima.

\section{Recheios construtivos}

Nas estruturas residenciais e de bairro, a ardósia é encontrada, com muita freqüência, no recheio construtivo dos pisos. A maior parte das ardósias provenientes de Teopancazco - um centro de bairro - examinadas por nós no Projeto Elite y Gobierno, dirigido pela Dra. Linda Manzanilla, eram fragmentos pequenos, a maioria com pintura de várias cores, e foram 
escavados em recheios de pisos. Do nosso ponto de vista, este é um contexto secundário relacionado aos enterramentos: ao extrair-se terra dos arredores para a construção, se revolvia os enterros aí existentes e se levavam junto restos ósseos e de oferendas funerárias. Daí que a maior parte dos fragmentos de ardósia recuperada em recheio construtivo apresenta pintura.

\section{Uso ritual}

Nos contextos propriamente rituais, a ardósia foi um item raro, o que parece revelar, ainda mais, o seu papel funerário. A pedra gris pode ser encontrada em alguns espaços rituais importantes, sem necessariamente constituir "oferendas". Na Pirâmide da Lua foi recuperado um disco de ardósia que funcionava como base para uma imagem de pedra verde (López Juárez 2005: 116), mas esse é um emprego que provavelmente estaria relacionado ao uso utilitário da ardósia, como base de espelhos, mosaicos, pendentes, objetos de madeira, pluma e mica (idem: 119); nos túneis da Pirâmide do Sol, Doris Heyden reporta haver encontrado um disco com representações de personagem oriundos da Costa do Golfo (idem: 116).

As oferendas dedicatórias realizadas no Templo de Quetzalcóatl, continham numerosos objetos de ardósia - discos, placas, fragmentos com restos de pigmento vermelho, figurinhas antropomórficas, contas, pendentes e outras formas não identificadas (Cabrera Cortés 1995: 173) - embora a presença dos guerreiros sacrificados envolva inevitavelmente a existência de alguns elementos relacionados à vida após a morte, estando assim, de algum modo relacionado com certos padrões do ritual funerário.

Linda Manzanilla (2001: 3) informa a presença de ardósia associada a discos de mica, restos ósseos, lítica, concha e pedras verdes em um ritual de terminação em Teopancazco onde se destruíram intencionalmente muitas vasilhas cerâmicas - mas não sabemos até que ponto a presença de ardósia associada a restos ósseos e outros bens não fariam parte de antigos terrenos usados para recheio.
Os registros da Ceramoteca da ZMATINAH inventariam uma série de objetos como pendentes, figuras antropomórficas, fragmentos fitomorfos, triangulares, e retangulares procedentes de pontos importantes, como a Plaza da Lua, Avenida dos Mortos, mas não apresentam detalhes de seus contextos, se seriam realmente oferendas.

Em alguns pontos é muito claro o papel exclusivamente funerário da ardósia: no Bairro dos Comerciantes, dos 44 depósitos escavados (28 enterros e 16 oferendas) a ardósia esteve presente apenas em enterros (Enterros 23, 5-8, $24-25,26,27$ a $, 29,32,3,15-16,19,33,30)$ e absolutamente nenhum objeto ou fragmento foi depositado em oferendas.

\section{Uso funerário}

É no contexto funerário, entretanto, que as ardósias se destacam por sua variedade de formas e simbolismo. Estas são reportadas em enterramentos de diversos conjuntos da cidade: Tlamimilolpan (Linné 1942), Tlajinga 33 (Storey e Widmer 1989), Oztohuayalco (Manzanilla 1993; 1996; 2002), La Ventilla (Gómez Chávez 2000), Bairro dos Comerciantes (Rattray 1997), Bairro Oaxaqueño (López Juárez 2005), Conjunto 1D da Cidadela, lado Norte do Templo de Quetzalcóatl (Jarquín Pacheco 2002), Atetelco (Dados da Ceramoteca da ZMAT-INAH). Das formas mencionadas acima, praticamente todas são encontradas em contexto funerário, ainda que nem sempre seu simbolismo seja fácil de interpretar.

As figuras antropomorfas que acompanham os mortos poderiam ter a função de esfinges. Em várias sociedades da Mesoamérica houve o costume de enterrar os mortos ou mesmo indivíduos sacrificados depositando entre as oferendas funerárias estas figuras, além de máscaras. $\mathrm{Na}$ maior parte das vezes e, sobretudo em Teotihuacan, tais figuras eram geralmente elaboradas em algum tipo de pedra verde, símbolo de vida e fertilidade, ou ainda em diorita, que se caracteriza por sua cor cinza chumbo. No caso das máscaras, Annabeth Headrick (1999) sugere que sua função era 
conservar a energia vital dos antepassados. Em outro trabalho, enfatizamos o papel das máscaras, figuras antropomórficas, contas e pedras que acompanhavam os defuntos como um receptáculo de suas forças anímicas (França 2005), com base na idéia de "esfinges" observada por López Austin (1994). Acreditamos que a função das figuras antropomórficas de ardósia deveria seguir por esse caminho.

As peças com listras vermelhas são ainda mais difíceis de interpretar (Fig. 5). As que chamamos fitomorfas constituem uma clara representação de folhas ou pétalas de flores, algumas delas com restos de um provável adesivo de cor café, amarelo escuro ou verde oliva, o que indica que provavelmente eram usadas como incrustações, nesse caso, na composição de flores, talvez no próprio vestuário do defunto. A aparência brilhante da ardósia, sua leveza e forma natural laminar, além de uma superfície fácil de ser polida e de receber pigmentos, a tornam muito apropriada para este tipo de uso. Nesse caso, é fundamental lembrar que as flores eram um importante símbolo de fertilidade dentro da cosmovisão mesoamericana do Período Pós-Clássico. Em Teotihuacan, o estudo da iconografia revela que a flor de quatro pétalas era um importante símbolo da superfície terrestre (o que envolve a noção de fertilidade) e do próprio domínio territorial teotihuacano, já que a própria

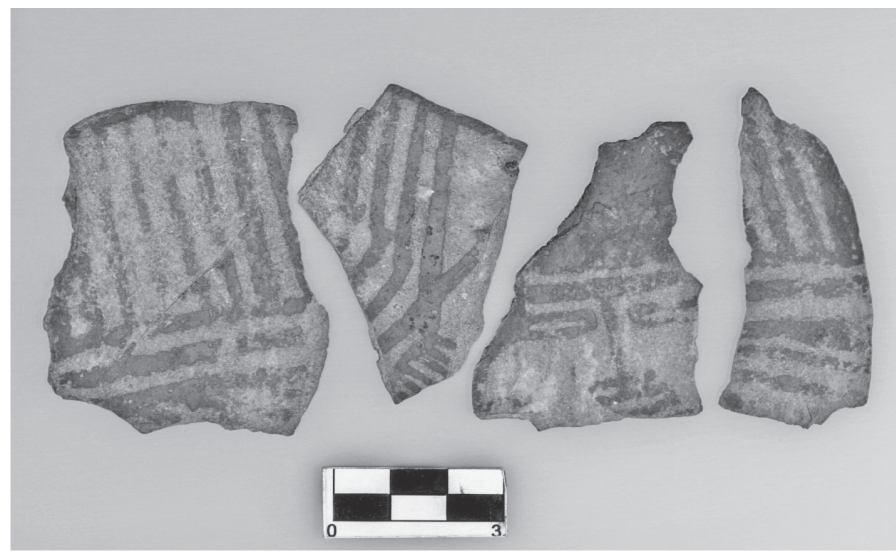

Fig. 5. Lâminas de ardósia pintadas de faixas vermelhas, símbolo de sangue e vida no além-túmulo. Enterro 74, La Ventilla, Teotihuacan. Foto: Miguel Morales. cidade era dividida em quatro quadrantes.

As peças do tipo "bico de ave" são para nós uma verdadeira incógnita, ainda que seja possível pensar que o atributo de aves poderia ter um significado mítico importante, já que diversas aves, entre elas o quetzal e a águia eram importantes na iconografia e na pintura mural teotihuacana. Algumas dessas também apresentam restos de adesivo e provavelmente eram usadas nas incrustações do vestuário. As formas geométricas deveriam ter, provavelmente, a mesma função.

Entretanto, a característica mais significativa desses materiais e crucial para sua interpretação é a sua pintura, freqüentemente com iconografia de listras vermelhas. López Juarez (2005) defende que essa iconografia se relaciona a um sistema de representações incipiente. Segundo ela, a ardósia pintada estaria relacionada ao inframundo e particularmente associada à cremação, representando conceitos importantes como a sobrevivência e a transformação. Para esta autora, a ardósia pintada poderia funcionar, ainda, como um "receptáculo de almas", a exemplo do jade e as pedras verdes.

Do nosso ponto de vista, as listras vermelhas podem constituir uma representação simbólica, nesse caso de vida e renascimento, já que nos parece uma inegável representação do sangue. Se o zinabre e outros pigmentos vermelhos eram empregados nos enterros como um símbolo do sangue e da vida no alémtúmulo (Gazzola 2000), é totalmente provável que os objetos com representações de listras vermelhas tivessem a função de representar o sangue que "escorre". Algumas peças ou fragmentos fitomorfos e do tipo "bico de ave" do Conjunto Tlamimilolpa examinadas por nós apresentaram um elemento que confirmam nossa suspeita: entre as listras vermelhas sobre um fundo branco, é possível observar o desenho do glifo "jade" (chalchihuitl) - símbolo 
inequívoco de vida e fertilidade. O chalchihuitl naturalmente era uma representação de gotas de água, mas possuía sua versão vermelha que podia representar o sangue ou "água preciosa" (chalchihuátl, no nahuatl do Pós-Clássico Tardio).

A idéia de "receptáculo de almas" (ou energias anímicas) é muito pertinente, já que essa é uma das funções simbólicas das pedras (Eliade 1993) e como sugere López Juárez, é possível que a ardósia tivesse um valor intrínseco, já que era comum a presença desse material em bruto em alguns contextos, como por exemplo, no Templo de Quetzalcóatl (Cabrera Cortés 1995). Não se pode esquecer, ainda, que o chalchihuitl representado em algumas peças aqui estudadas - em sua forma original, ou seja, a conta de jade, constituía o mais importante receptáculo de forças anímicas em diferentes sociedades mesomericanas.

Os espelhos de pirita constituem um caso à parte. Esses discos de ardósia que variavam de 4 a $15 \mathrm{~cm}$ de diâmetro tinham incrustado na face principal um mosaico de pirita dourada reluzente. Os espelhos escavados são discos de ardósia com restos de uma substancia amarela com inclusões café ou ocre em uma das faces, que corresponde aos restos de pirita transformada pelo tempo (Figs. 6 e 7).

Possuindo em media $0,5 \mathrm{~cm}$ de espessura, esses objetos normalmente apresentam traços de trabalho bastante especializados, com superfícies planas e bordas bem acabadas e na maioria dos casos, perfuração que teriam como função pendurá-los junto ao corpo.

A presença dos espelhos de pirita poderia explicar-se simplesmente pelo fato de que estes objetos constituíam um importante item na ornamentação da camada dirigente e sacerdotal. Entretanto, os espelhos podem ter tido funções muito específicas no contexto funerário. Segundo Karl Taube (1992) estes teriam várias funções, a primeira delas como parte do vestuário, usada nas costas, especificamente na região lombar - o que se confirma pelos espelhos associados aos guerreiros sacrificados no Templo de Quetzacoátl que o levavam junto a esta região do corpo (Sugiyama 1989).

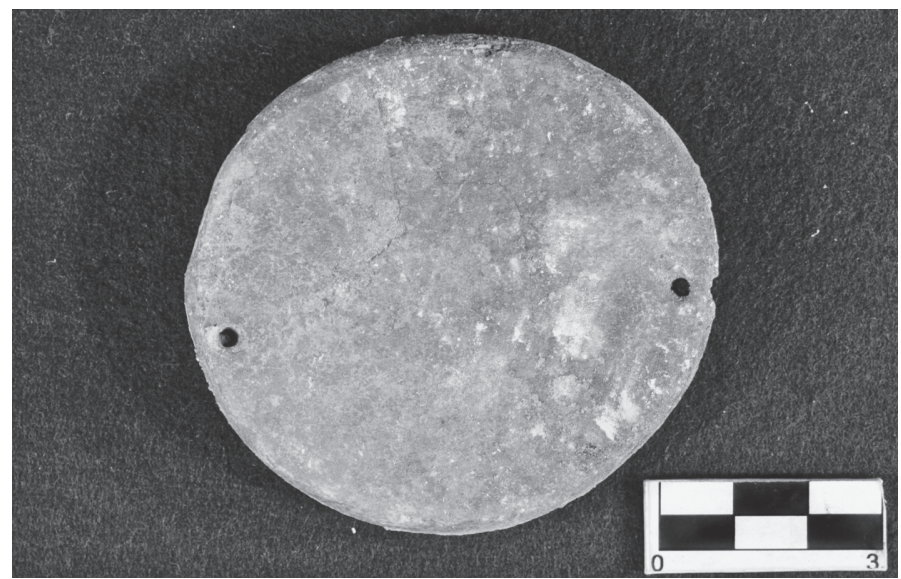

Fig. 6. Disco de ardósia que servia de base aos espelhos de pirita (Tezcacuitlapillis). Conjunto 1D- A cidadela, Enterro 204-C. Proyecto Arqueológico Teotihuacan 1980-82. Foto: Miguel Morales.

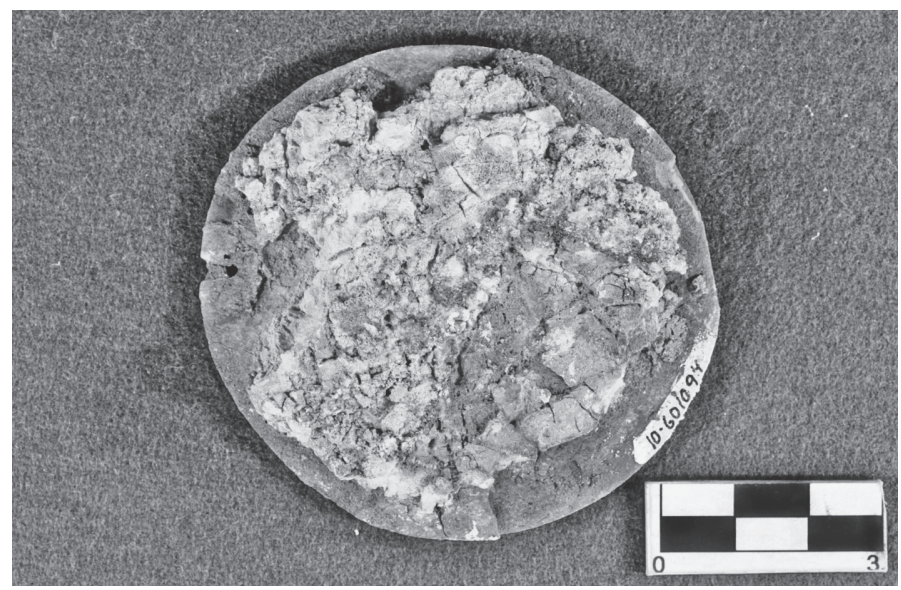

Fig. 7. Restos de pirita transformada na face anterior de um espelho com base em disco de ardósia. Conjunto 1D- A Cidadela, Enterro 204. C. Proyecto Arqueológico Teotihuacan 1980-82. Foto: Miguel Morales. 
Também podiam ser usados no peito ou no toucado. Segundo o mesmo autor, os espelhos eram essencialmente objetos de adivinhação, simbolizando diversos elementos essenciais da cosmovisão: o "olho", a "face", o "fogo", a “água”, uma "rede ou teia de aranha”, um "escudo tecido de plumas", o "Sol" ou uma "caverna" (Taube 1992).

Todos esses elementos são extremamente representativos dentro da cosmovisão mesoamericana e alguns deles são muito significativos em um contexto funerário. Nas várias sociedades da Mesoamérica, um espelho de adivinhação funcionava como um canal de comunicação com o mundo sobrenatural e tanto o "olho" como a "face" eram as suas metáforas mais importantes, sendo que a última podia encarnar personalidades divinas (idem: 183). Por sua vez, água, fogo, e o Sol, elementos básicos para a vida, representavam conceitos fundamentais para a sobrevivência como a fertilidade, a vida, o tempo e outros mais relacionados com a ordem cósmica. A identificação do espelho como uma rede ou teia de aranha pode estar relacionada com a própria aparência do mosaico de pirita ainda que seu simbolismo não seja comentado pelo autor (idem: 189) e o escudo tecido de plumas poderia evocar a idéia de proteção (idem: 192). A idéia de um espelho como uma caverna é extremamente significativa: as cavernas eram consideradas um ponto de contato com o mundo sobrenatural, e segundo o mesmo autor, "os espelhos de Teotihuacan foram passagens vitais pelas quais os deuses e ancestrais se comunicavam com o mundo dos vivos" (idem: 197, tradução nossa).

Restam poucas dúvidas, portanto, acerca da importância dos espelhos de pirita que acompanhavam os mortos. Em qualquer dos simbolismos mencionados ou de sua combinação, os espelhos de pirita eram instrumentos de contato e comunicação com o "outro mundo" para onde se dirigiam os mortos.

Os espelhos de pirita têm sido associados, igualmente, à atividade militar. Nas oferendas dedicatórias do Templo de Quetzalcóatl (Fig. 8) esses objetos estavam localizados na região lombar dos indivíduos sacrificados, ricamente adornados, e com as mãos amarradas às costas (Cabrera Cortés 1995; Sugiyama 1989). Já no Bairro dos Comerciantes temos um contexto diferente, já que um espelho estava diretamente associado a uma mulher jovem, no Enterro 26 e, indiretamente, juntamente com outros três indivíduos do sexo masculino, no enterro 24-25. Neste caso, deve-se pensar em duas possibilidades: 1 . este não é um objeto exclusivo de uma camada de guerreiros e sim das camadas privilegiadas de um modo geral; ou 2. que os comerciantes em Teotihuacan, ainda sendo estrangeiros, tivessem algumas das prerrogativas e reconhecimentos militares do mesmo tipo que os dos comerciantes do PósClássico (pochtecas), devido aos riscos que corriam em suas empresas e ao apoio do Estado teotihuacano a um tipo de atividade vital para sua manutenção.

Os anéis são uma forma encontrada exclusivamente no Bairro dos Comerciantes, especificamente nos Enterros 5-8 e 26. Do nosso ponto de vista isso não é mera coincidência: a forma circular dos anéis parece estar de acordo com o tipo de arquitetura circular do bairro, procedente da região do Golfo muito distinta do padrão teotihuacano - e é muito provável que fosse um símbolo de identidade do grupo.

\section{Comentários finais}

Tais informações demonstram claramente que não foi pequeno o impacto da ardósia sobre a vida econômica e ritual de Teotihuacan. Ainda que não fosse um material raro como o jade, e provavelmente não sujeito às mesmas restrições de uso, a ardósia era uma artigo importado, cuja entrada deveria ser relativamente regulamentada, e sua importação sem dúvida representava um negócio importante na política externa e no estabelecimento de enclaves comerciais da metrópole teotihuacana.

As oficinas lapidárias identificadas revelam que a ardósia era normalmente trabalhada em bairros, na confecção de adornos e objetos rituais para o emprego funerário de camadas altas e medias da sociedade e, no caso específi- 


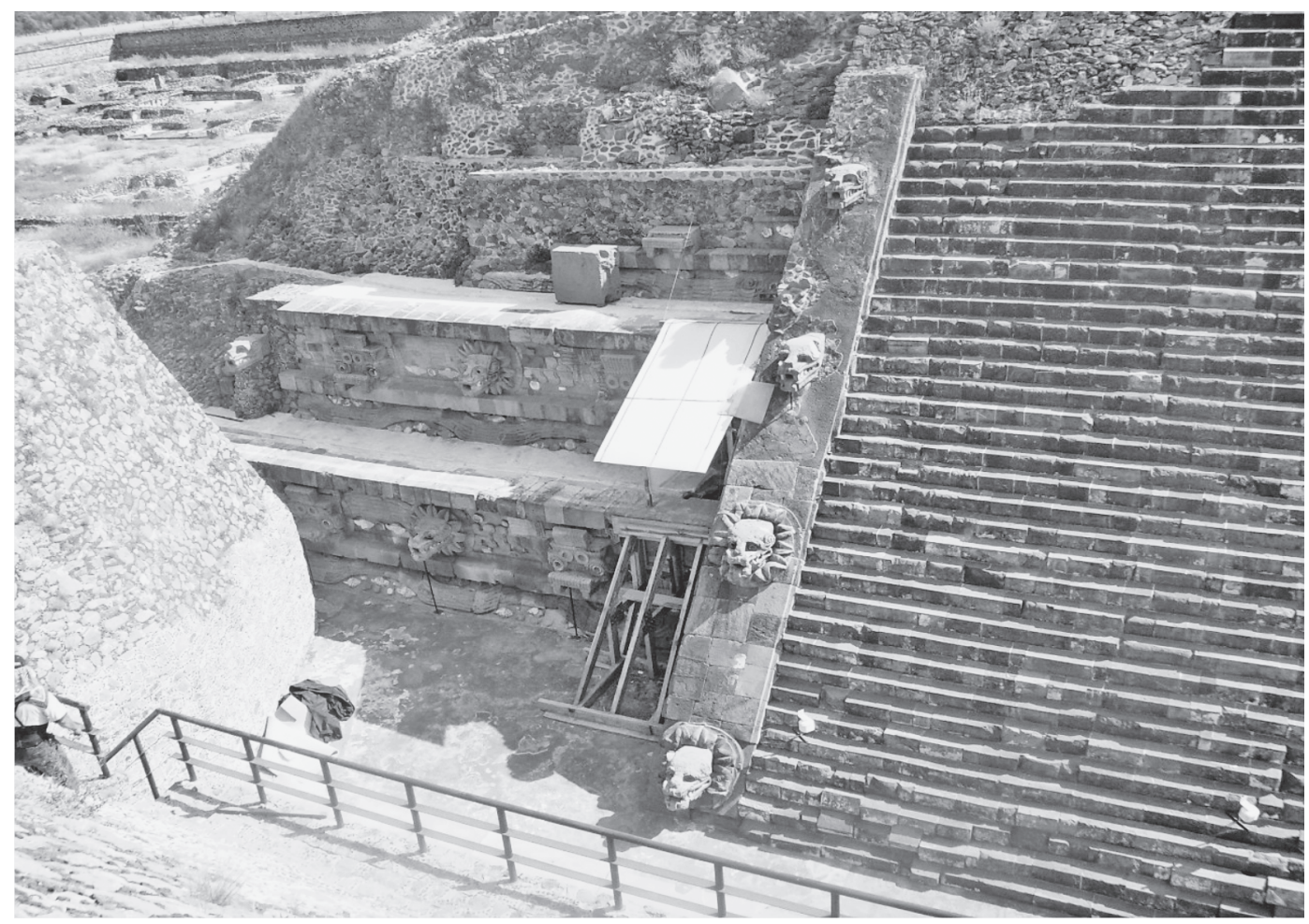

Fig. 8. Templo de Quetzalcóatl. Foto Lucas França.

co do espelho de pirita - um artigo destinado a elementos de grande importância social - em oficinas estatais especializadas como o máximo de controle estatal. Dada a sua relevância na decoração do vestuário e dos edifícios e principalmente por sua importância simbólica em contextos funerários e a julgar pela quantidade de ardósia encontrada nessas oficinas espalhadas por vários pontos da cidade, este era um artigo significativo dentro da organização do trabalho e das atividades artesanais em Teotihuacan.

Finalmente, o simbolismo funerário da ardósia revela que esta matéria-prima desempenhou um papel de primeiro plano na materialização de conceitos da mais alta relevância dentro da religião teotihuacana, cujos temas centrais eram vida, renascimento e fertilidade.

\section{Agradecimentos}

Meus agradecimentos à Ceramoteca da Zona de Monumentos Arqueológicos de Teotihuacan, INAH-México - pelo acesso aos materiais, aos dados de arquivo e pelas fotos de autoria de Miguel Morales - e às Dras. Evelyn Childs Rattray e Linda Manzanilla do IIA-UNAM, pela participação em seus respectivos projetos. Agradeço, ainda, ao CNPq pela bolsa de Pós-doutorado no Exterior que viabilizou a realização do Projeto "A ardósia e as pedras verdes em três conjuntos teotihuacanos: padrões de distribuição e de culto". 
FRANÇA, L.M. The use of slate in Teotihuacan, Mexico. Revista do Museu de Arqueologia e Etnologia, São Paulo, 17: 333-343, 2007.

Abstract: One of the most important activities in Teotihuacan was the lapidary industry. Among the raw material more worked on, slate was used to make personal adornments, ritual and funerary gifts. Its social and symbolic relevance indicates its impact on state control over productive zones, commercial routes and the craftwork production system so important to the consolidation and maintenance of the teotihuacan State.

Keywords: Lapidary industry - Slate - Teotihuacan - Mesoamerica.

\section{Referências bibliográficas}

CABERA CORTÉS, M.O.

1995 La Lapidaria del Proyecto Templo de Quetzalcóatl 1988-1989. México: ENAH.

ELIADE, M.

1993 Tratado de historia das religiões. São Paulo: Martins Fontes.

FRANÇA, L.

2005 O monte das águas-queimadas: o simbolismo das oferendas no Templo Mayor de Tenochtitlan. São Paulo, Tese de Doutorado, Museu de Arqueologia e Etnologia-USP.

GAZZOLA, J.

2000 Los usos de cinabrio en Teotihuacan. Tese de Doutorado, Sorbonne, Paris I.

GÓMEZ CHÁVEZ, S.

2000 La Ventilla. Un barrio de la antigua ciudad de Teotihuacan. México. Tese de Licenciatura ENAH/INAH.

HEADRICK, A.

1999 The street of the dead...it really was. Ancient Mesoamerica, 10: 69-85.

JARQUÍN P., A.M.

2002 El Conjunto Norte y Lado Este de la Ciudadela: análisis de contextos arqueológicos del Periodo Clásico desde la perspectiva de la Etnohistoria. FFL/IIF-UNAM, México.

LINNÉ, S.

1942 Mexican Highlands Cultures. Archaelogical Researches at Teotihuacan, Calpulalpan and Chalchicomula in 1934-35. New Series, Publication 7. Ethnographical Museum of Sweden, Estocolmo.

LÓPEZ AUSTIN, A.

1994 Tamoanchan y Tlalocan. México: FCE.
LÓPEZ JUÁREZ, J. M.

2005 La Pizarra en la Antigua Ciudad de Teotihuacan. Tipología e Interpretación. Tesis de Licenciatura. México, ENAH.

MANZANILLA, L.

1993 Anatomía de un conjunto residencial en Oztoyahualco, México, UNAM, Vol. I, II, III.

1996 Corporate Groups and Domestic Architecture at Teotihuacán. Latin American Antiquity, 7 (3): 228-246.

2001 Teopancazco, un conjunto residencial de Teotihuacan. Tezontle. Boletín del Centro de Estudios Teotihuacanos, 5, Abril, Mayo, Junio: 2-4.

2002 Living with the Ancestors and Offering to the Gods. Domestic Ritual at Teotihuacan. In: Plunket, P. (Ed.) Domestic Ritual in Ancient Mesoamerica. Los Angeles, University of California: 43-53.

MILLON, R.

1973 Urbanization at Teotihuacan. Teotihuacan Mapping Project. Austin: University Texas Press.

1995 The Last years of Teotihuacan Dominance. In: Yoffe, N.; Cowgill, G.L. (Eds.) The Collapse of Ancient States and Civilizations. Tucson, The University of Arizona Press: 102-164.

RATTRAY, E.C.

1987 Los barrios foráneos de Teotihuacan. In: McClung de Tapia, E.; Rattray, E.C. (Eds.) Teotihuacan. Nuevos datos, nuevas sintesis, nuevos problemas. México, UNAM: 243-273. 
1988 Nuevas interpretaciones del barrio de los comerciantes. Anales de Antropología, México, XXV: 165-180.

1997 Entierros y Ofrendas en Teotihuacan. Excavaciones, inventario, patrones mortuorios. México: IIA-UNAM.

2001 Teotihuacan. Cerámica, cronología y Tendencias culturales (Ed. Bilingüe), INAH/University of Pittisburgh, Série Arqueología de México.

SPENCE, M.W.

1881 Obsidian production and the state in Teotihuacan. American Antiquity, 46 (4): 769-788.

STOREY, R.; WIDMER, R.J.

1989 Household and Community Structure of a Teotihuacan Apartment Coumpound: S3W1:33 of the Tlajinga Barrio. MacEachern, S.; Acher, D.J.W.; Garvin, R.D. (Eds.) Household and Communities. The Archaeological Association of the University of Calgari, Calgary: 407-415.
SUGYIAMA, S.

1989 Burials dedicated to the Old Temple of Quetzalcóatl at Teotihuacan, Mexico. American Antiquity, 54 (1): 85-106.

TAUBE, K.

1992 The Iconography of Mirrors at Teotihuacan. In: Berlo, J.C. (Ed.) Art, Ideology and the City of Teotihuacan. Washington, D.C., Dumbarton Oaks: 169-204.

TURNER, M.

1992 Style in Lapidary Technology: Identifying the Teotihuacan Lapidary Industry. In: Berlo, J.C. (Ed.) Art, Ideology and the City of Teotihuacan. Washington, D.C., Dumbarton Oaks: 89-112.

WIDMER, R.J.

1991 Lapidary Craft Specialization at Teotihuacan: Implications for Community Structure at 33:S3W1 and Economic Organization in the City. Ancient Mesoamerica, 2 (1) Spring. New York, Cambridge University Press: 131-147. 